\title{
Use of prescription analgesic drugs before and after hip or knee replacement in patients with osteoarthritis
}

\author{
Tuomas J. Rajamäki Jr ${ }^{1 *}$ (D), Pia A. Puolakka², Aki Hietaharju ${ }^{1,3}$, Teemu Moilanen ${ }^{4}$ and Esa Jämsen ${ }^{1,4}$
}

\begin{abstract}
Background: Analgesic drugs are recommended to treat pain caused by osteoarthritis, and joint replacement should decrease the need for them. We aimed to determine the user rates of analgesic drugs before and after joint replacement.
\end{abstract}

Methods: All patients who underwent a primary hip or knee replacement for osteoarthritis from 2002 to 2013 in a region of 0.5 million people were identified. Patients with revision or other joint replacements during the study period (operation date +/- two years) were excluded, leaving 6238 hip replacements (5657 patients) and 7501 knee replacements (6791 patients) for analyses. Medication data were collected from a nationwide Drug Prescription Register and the prevalence (with its 95\% confidence intervals) of acetaminophen, non-steroidal anti-inflammatory drugs (NSAIDs), mild opioids, strong opioids, and medications used for neuropathic pain was calculated in threemonth periods two years before and after surgery.

Results: Between two years and three months preoperatively, the proportion of patients who redeemed at least one type of analgesic drug increased from $28 \%(95 \% \mathrm{Cl}, 27-30 \%)$ to $48 \%(47-50 \%)$ on hip replacement patients and from 33\% (32-34\%) to 41\% (40-42\%) on knee replacement patients. Postoperatively, the proportions decreased to $23 \%(22-24 \%)$ on hip and to $30 \%$ (29-31\%) on knee patients. Hip replacement patients used more NSAIDs (34\% (32-35\%) hip vs $26 \%(25-27 \%)$ knee, $p<0.001)$, acetaminophen (14\% (13-15\%) vs 12\% (11-13\%), $p<0.001)$, and mild opioids $(14 \%(13-15 \%)$ vs $9 \%(8-9 \%), p<0.001)$ than knee patients preoperatively, but postoperatively hip patients used less NSAIDs (12\% (11-13\%) vs 16\% (15-16\%), $p<0.001)$, acetaminophen (9\% (8-10\%) vs 11\% (11-12\%), $p<0.001)$, and mild opioids (5\% (5-6\%) vs $8 \%(7-8 \%), p<0.001)$.

Conclusion: Use of analgesic drugs increases prior to joint replacement, and is reduced following surgery. However, a considerable proportion of patients continue to use analgesics in two-year follow-up.

Keywords: Arthroplasty, Analgesics, Drug prescriptions, Opioids, Non-steroidal anti-inflammatory drugs, Acetaminophen

\section{Background}

Pain is the most common symptom of osteoarthritis $(\mathrm{OA})$, and current guidelines for the management of hip and knee OA recommend the use of both nonpharmacological and pharmacological treatment options [1-5]. For those patients who do experience insufficient pain relief with conservative treatment,

\footnotetext{
* Correspondence: tuomas.rajamaki@tuni.fi

${ }^{1}$ Faculty of Medicine and Health Technology, Tampere University, Fl-33014

Tampere, Finland

Full list of author information is available at the end of the article
}

joint replacement is recommended [6-8]. Nevertheless, 8 to $27 \%$ of knee replacement and 5 to $21 \%$ of hip replacement recipients suffer from persistent postoperative pain [9].

At present, it is not completely known what proportion of patients use analgesic drugs before and after joint replacement. It has been estimated that nearly half of all knee osteoarthritis patients use pain medication, mostly over-the-counter (OTC) or prescription non-steroidal anti-inflammatory drugs (NSAID) and acetaminophen [10]. Supposedly, the proportion of patients using pain

(c) The Author(s). 2019 Open Access This article is distributed under the terms of the Creative Commons Attribution 4.0 International License (http://creativecommons.org/licenses/by/4.0/), which permits unrestricted use, distribution, and reproduction in any medium, provided you give appropriate credit to the original author(s) and the source, provide a link to the Creative Commons license, and indicate if changes were made. The Creative Commons Public Domain Dedication waiver (http://creativecommons.org/publicdomain/zero/1.0/) applies to the data made available in this article, unless otherwise stated. 
medication would be greater in those waiting for joint replacement, and it should decrease postoperatively. The proportion of hip and knee replacement recipients using analgesic drugs preoperatively varies from 48 to $94 \%$, depending on methodology of the study [11-15]. The most commonly used drugs are acetaminophen, NSAIDs, and mild opioids [11-15]. These practices are also in accordance with current guidelines for the pharmacological treatment of osteoarthritis $[1,2,4]$.

Several recent studies have examined opioid use after joint replacement [16-18], but only a few studies have examined overall analgesic consumption both before and after surgery $[11,13,15,19-21]$. Prescription data on total hip replacement patients indicate an increase in the use of analgesics (both opioids and non-opioids) during the year before surgery, followed by a peak occurring immediately after surgery and then a decrease during the first postoperative year [13]. In the field of knee replacement, again, previous studies have mainly focused on the risk factors for increased postoperative analgesic consumption $[11,15,19$, 21 ] or only on the consumption of NSAID's [20]. Moreover, only a few studies have included medications used for neuropathic pain $[11,13-15,18]$, although a remarkable share of joint replacement patients suffer from persistent postoperative pain [9] that may be treated with such drugs. Therefore, research on the consumption of analgesic drugs in joint replacement patients should include all analgesic drugs, and not only acetaminophen, NSAID's, and opioids.

The aim of this study was to provide a detailed description of consumption trajectories for all prescription analgesic drugs two years before and after hip or knee replacement.

\section{Methods}

\section{The study population}

All hip and knee replacement operations in the Pirkanmaa hospital district (population 0.5 million) in Finland are performed in a single orthopedic hospital. Between 2 September 2002 and 31 December 2013, 26,466 operations (13,261 hip replacements and 13 , 205 knee replacements) were performed on 20,068 patients at the hospital. Preoperative and postoperative information on these patients was collected from the prospective joint replacement database of the hospital. In this study, the inclusion criteria were primary operation and primary osteoarthritis being the indication for surgery. Patients with revisions or other joint replacements during the study period (operation date +/- two years) were excluded, leaving 6238 hip replacements (5657 patients) and 7501 knee replacements (6791 patients) for analyses (Fig. 1).

\section{Medication data}

In Finland, the conservative treatment of osteoarthritis is primarily the responsibility of general practitioners. If conservative treatment is insufficient, patients are referred for consideration for joint replacement [5]. Postoperatively, analgesics are first prescribed by surgeons, whereas general practitioners prescribe analgesics in longer follow-up.

All medications in Finland are dispensed from licensed pharmacies. The Social Insurance Institution of Finland maintains a nationwide Drug Prescription Register that contains information on all prescribed medications that have been dispensed in Finland. In this study, information on the Anatomical Therapeutic Chemical (ATC) code of dispensed drugs, the number of units dispensed (tablets or patches), and the date of purchase was collected from the Drug Prescription Register. Prescription data were linked to joint replacement data using the unique personal identification code assigned to all Finnish residents.

The included medications were classified into subgroups according to their ATC codes as follows: acetaminophen (N02BE01), non-steroidal anti-inflammatory drugs (NSAID) (M01A), mild opioids (N02AA59, N02AX02, N02AE01), strong opioids (N02AA01, N02AA03, N02AA05, N02AB03), medications used for neuropathic pain (N03AX12, N03AX16, N06AA09, N06AA10, N06AX16, N06AX21, i.e., gabapentin, pregabalin, amitriptyline, nortriptyline, venlafaxine, and duloxetine), and any analgesic drug (all previous groups combined). Transdermal buprenorphine patches were classified as mild opioids and transdermal fentanyl patches were classified as strong opioids. Oral buprenorphine and fentanyl as well as oral liquid products of all opioids were excluded because they are used for pain caused by other reasons than osteoarthritis, like cancer pain. Transdermal gel products and oral liquid products of NSAID's were excluded from this study.

\section{Statistics}

The proportions (with 95\% confidence intervals) of patients who redeemed at least one prescription of a medication were calculated in time-periods of three months (90 days) during the 4-year observation period. Threemonth periods were chosen because Finnish pharmacies are only allowed to give patients a 90-day supply of prescribed medication at a time. It was recorded, whether a patient had redeemed at least one prescription of a studied medication at a corresponding quartile. The eight quartiles before the operation are referred to as the preoperative period and the eight quartiles after the operation as the postoperative period.

The primary outcome was the detailed description of the analgesic consumption trajectories of the various drug classes two years before and after surgery. An expression 'user rate' is used as a synonym for the proportion of patients who redeemed drugs in a specific time- 


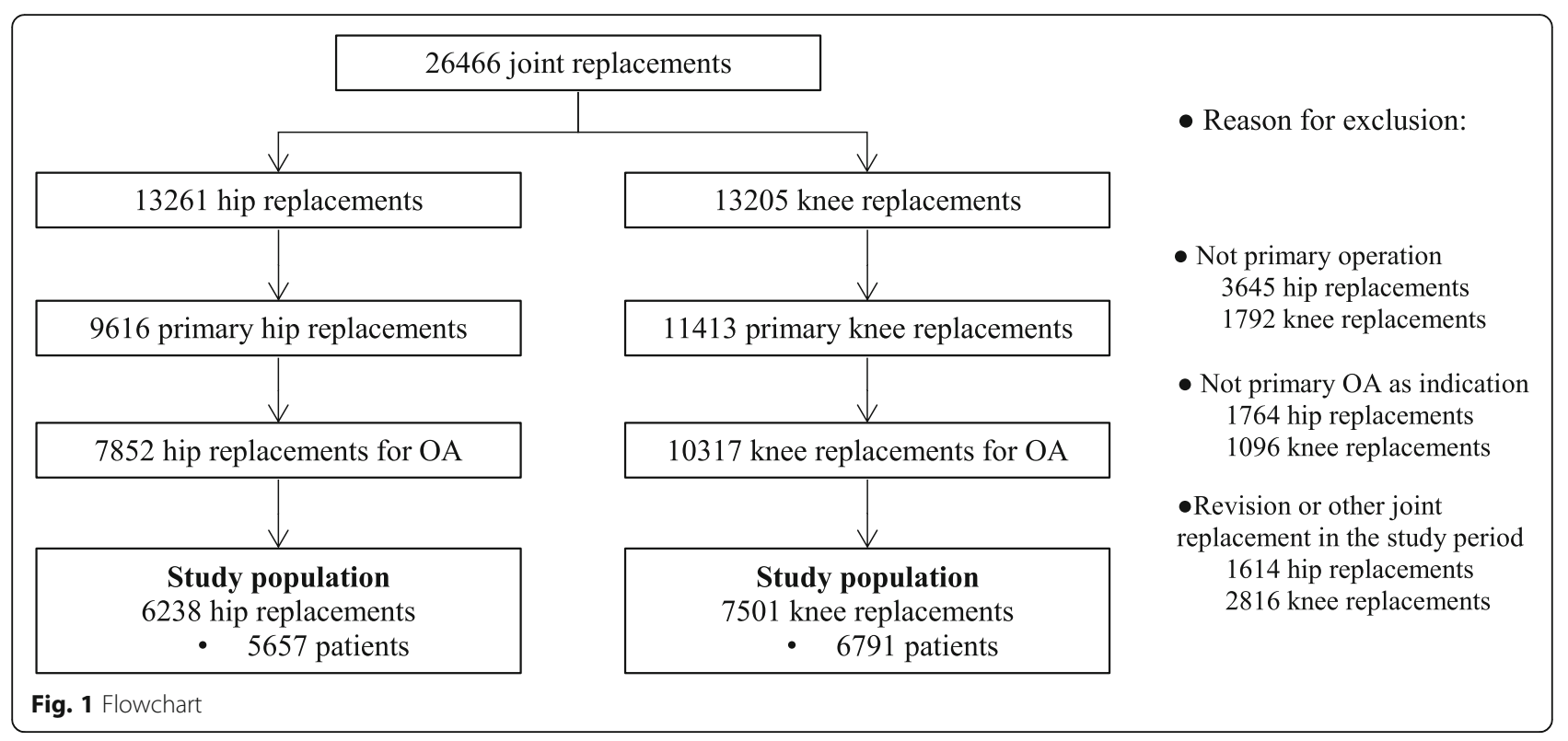

period. Analgesic consumption on late preoperative period (three months preoperatively) was compared to early preoperative consumption (two years preoperatively) and late postoperative (two years postoperatively) consumption. The primary outcome was first analyzed in the whole study population and then in the subgroups according to joint (hip versus knee), gender, and age (< 65 years, 65 to 75 years, $>75$ years). Finally, an additional analysis was made to determine the proportions of patients who continued to use analgesic drugs after surgery and the proportion of patients who were new users. In this analysis, the patients were divided into subgroups based on information whether they had redeemed analgesics during the year before surgery or not.

The analyses were performed using IBM SPSS Statistics 24. Bilateral operations were analyzed as one. Parametric variables are presented with mean and standard deviation (SD) and categorical variables with numbers and percentages. Unpaired T-test was used to compare parametric variables and chi-square test was used to compare categorical variables. $P$-values of $<0.05$ were considered statistically significant.

\section{Results}

\section{Study population}

The study population was an unselected populationbased cohort of OA patients undergoing joint replacement surgery. The mean age was 68.7 years (SD 10.1) and majority (61\%) were women (Table 1$)$. Knee replacement patients were older and more often women than hip patients (Table 1). A bilateral operation was performed in $7 \%$ of hip and $16 \%$ of knee replacements patients.

\section{All patients}

During the 4-year observation period, 92\% (95\% CI, 91-93\%) of the hip replacement patients and 94\% (93-94\%) of the knee replacement patients redeemed at least one analgesic drug prescription.

Table 1 Demographic characteristics

\begin{tabular}{lll}
\hline & Hip replacement & Knee replacement \\
\hline Total number, n (\%) & 6238 & 7501 \\
Gender, female, n (\%) & $3319(53.2 \%)$ & $5077(67.7 \%)$ \\
Age, mean (SD), years & $67.6(10.6)$ & $69.7(9.5)$ \\
Bilateral operation, n (\%) & $418(6.7 \%)$ & $1225(16.3 \%)$ \\
BMIl $^{\text {a }}$ mean (SD), years & $28.2(4.7)$ & $29.9(4.8)$ \\
Diabetes $_{\text {Neurodegenerative disease }}{ }^{\mathrm{b}}$ & $473(7.6 \%)$ & $744(9.9 \%)$ \\
Cardiac disease $^{c}$ & $66(1.4 \%)$ & $111(1.5 \%)$ \\
Pulmonary disease & $373(6.0 \%)$ & $904(12.1 \%)$ \\
Hypertension & $1656(26.5 \%)$ & $2491(33.2 \%)$ \\
Epilepsy & $67(1.1 \%)$ & $74(1.0 \%)$ \\
History of malignancy & $182(2.9 \%)$ & $273(3.6 \%)$ \\
ASA score & & \\
1 & $637(10.2 \%)$ & $373(5.0 \%)$ \\
2 & $2398(38.4 \%)$ & $2910(38.8 \%)$ \\
3 & $1766(28.3 \%)$ & $2590(34.5 \%)$ \\
4 & $90(1.4 \%)$ & $97(1.3 \%)$ \\
missing & $1347(21.6 \%)$ & $1531(20.4 \%)$ \\
\hline
\end{tabular}

$\mathrm{SD}=$ standard deviation

${ }^{a}$ Body mass index; missing information on 866 (13.9\%) of hip and 1042

(13.9\%) of knee replacement patients

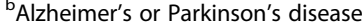

'coronary artery disease, heart failure, chronic arrythmia 


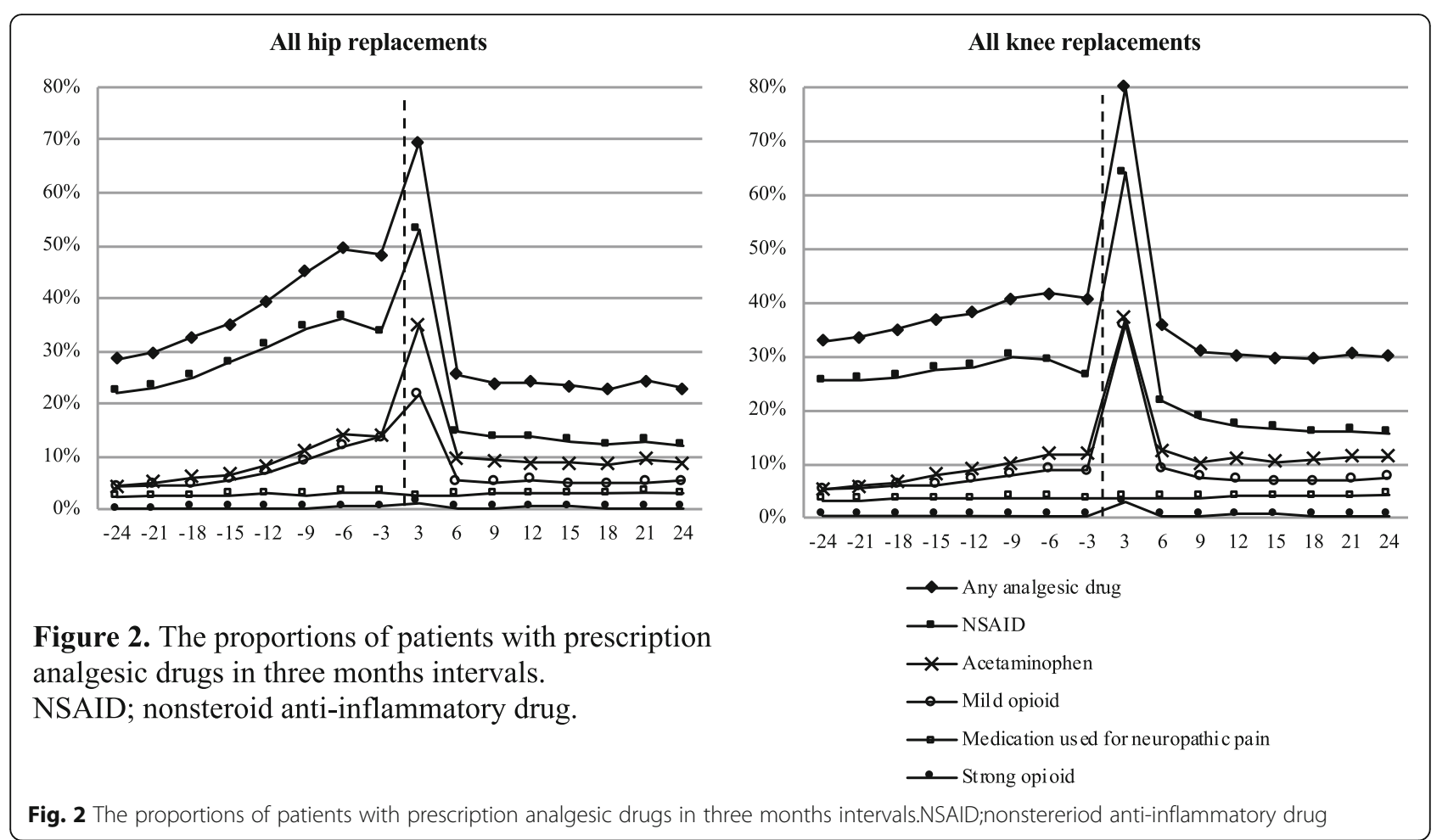

The proportion of patients who redeemed at least one type of analgesic drug prescription increased before the surgery (Fig. 2, Table 2). Two years before the surgery, $28 \%(27-30 \%)$ of hip patients and 33\% (32-34\%) of knee patients redeemed a prescription for at least one type of analgesic drug. By three months before the surgery, the proportions had increased to $48 \%(47-50 \%)$ and $41 \%$ (40$42 \%)$. After surgery, the use of all analgesics declined and the user rates decreased approximately to the level 2 years before surgery (Fig. 2, Table 2). The preoperative increase was especially attributable to the use of acetaminophen, NSAID's, and mild opioids in hip patients and to acetaminophen and mild opioids in knee patients. The proportion of patients using NSAIDs decreased in both hip and knee patients in the late preoperative period (Fig. 2).

In supplementary analysis, the drug use was analyzed in one year periods, and $73 \%(72-74 \%)$ of hip patients and $67 \%$ (66-68\%) of knee patients redeemed at least one prescription one year before the surgery (Appendix 1).

A peak in the number of patients who redeemed medication was seen in the immediate postoperative period for all analgesic drugs. After the immediate postoperative period, fewer hip patients redeemed analgesics (except strong opioids) than knee patients: Two years after surgery any analgesics were redeemed by $23 \%$ of hip and $30 \%$ of knee patients $(p<0.001)$, acetaminophen by $9 \%$ of hip and $11 \%$ of knee patients $(\mathrm{p}<0.001)$, NSAID by $12 \%$ of hip and $16 \%$ of knee patients, mild opioid by $5 \%$ of hip and $8 \%$ of knee patients $(\mathrm{p}<0.001)$ and medication used for neuropathic pain by $3 \%$ of hip and $4 \%$ of knee patients $(\mathrm{p}<0.001)$ (Fig. 2$)$.

The most common analgesic drugs throughout the study period were NSAIDs, except on patients $>75$ years old who redeemed more often acetaminophen than NSAID's in the late postoperative period (Table 2). Three months before the surgery, 34\% (95\% CI: $32-35 \%)$ of hip replacement patients and 26\% (25$27 \%)$ of knee patients redeemed NSAIDs, followed by acetaminophen $(14 \%(13-15 \%)$ of hip patients and $12 \%(11-13 \%)$ of knee patients), mild opioids (14\% (13-15\%) and 9\% (8-9\%)), medications used for neuropathic pain $(3 \%(3-4 \%)$ and $4 \%(3-4 \%))$, and strong opioids $(0.5 \%(0.3-0.6 \%)$ and $0.4 \%(0.3-0.5 \%)$, respectively) (Table 2).

Those patients who had redeemed analgesics preoperatively also redeemed them more often postoperatively compared to those patients who had not redeemed analgesics preoperatively $(p<0.001)$ (Table 3). Of the patients who had not redeemed analgesics three months preoperatively, a higher proportion of knee patients (19\%) than hip replacement patients (13\%) redeemed any analgesics two years postoperatively $(\mathrm{p}<0.001)$.

\section{Gender}

In both operation types, the proportions of patients who redeemed at least one type of analgesic drug, acetaminophen, NSAIDs, and mild opioids, were 


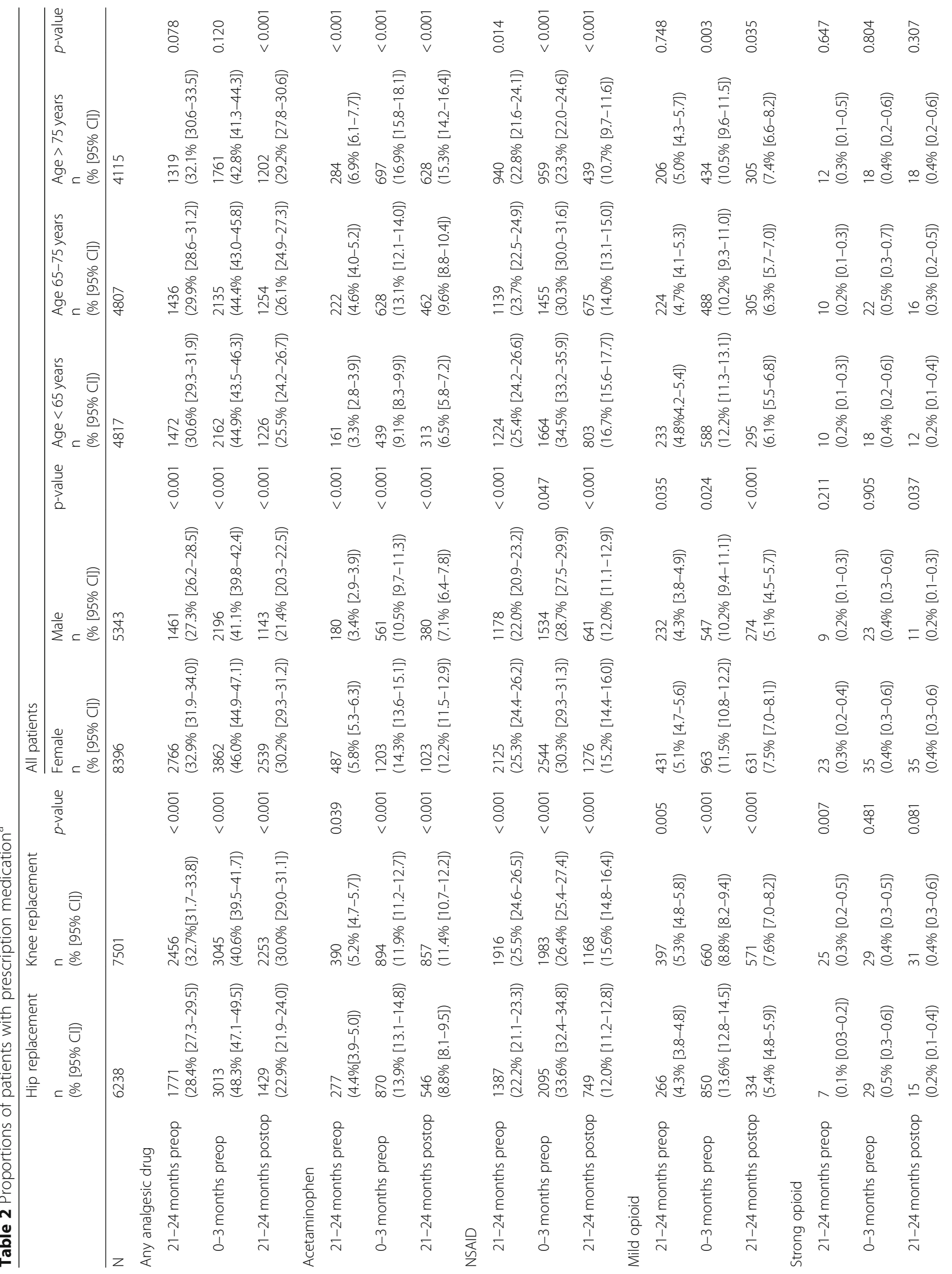




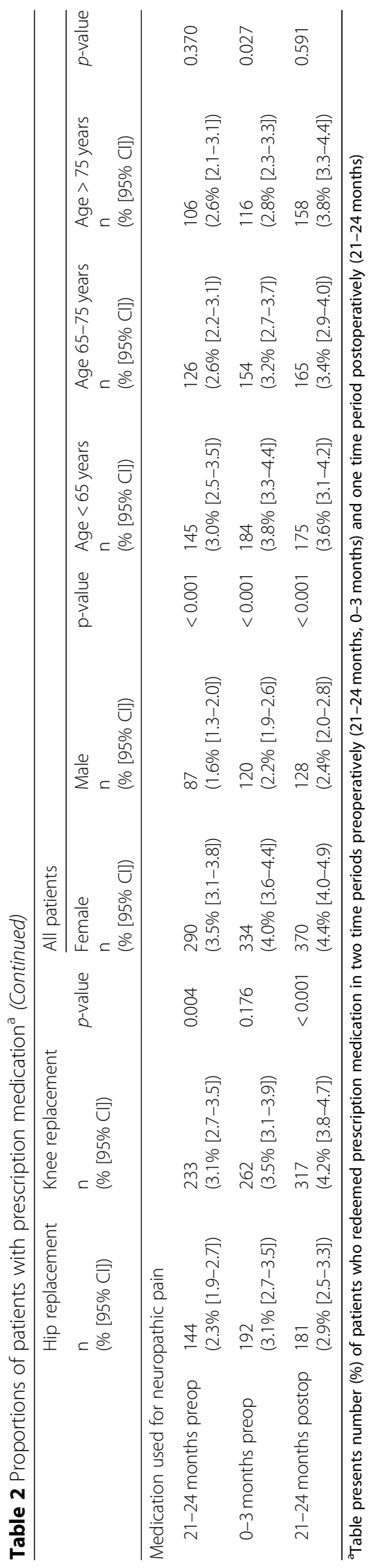


Table 3 The proportions of hip and knee replacement patients who continued to redeem analgesics ${ }^{\mathrm{a}}$ or were new to redeem analgesics ${ }^{\mathrm{b}}$ postoperatively

\begin{tabular}{|c|c|c|c|c|c|}
\hline & \multirow{2}{*}{$\begin{array}{l}\text { Preoperative } \\
0-3 \text { months preop }\end{array}$} & \multicolumn{4}{|c|}{ Proportion of patients who redeemed analgesics postoperatively } \\
\hline & & $0-3$ months postop & 3-6 months postop & 9-12 months postop & 21-24 months postop \\
\hline \multicolumn{6}{|l|}{ Any analgesic drug } \\
\hline Preoperative use $\mathrm{a}^{\mathrm{a}}$ & 6058 & $\begin{array}{l}5141 \\
(84.9 \%)\end{array}$ & $\begin{array}{l}2933 \\
(48.4 \%)\end{array}$ & $\begin{array}{l}2591 \\
(42.8 \%)\end{array}$ & $\begin{array}{l}2424 \\
(40.0 \%)\end{array}$ \\
\hline \multirow[t]{2}{*}{ No preoperative use ${ }^{b}$} & 7681 & $\begin{array}{l}5205 \\
(67.8 \%)\end{array}$ & $\begin{array}{l}1331 \\
(17.3 \%)\end{array}$ & $\begin{array}{l}1187 \\
(15.5 \%)\end{array}$ & $\begin{array}{l}1258 \\
(16.4 \%)\end{array}$ \\
\hline & & $p<0.001$ & $p<0.001$ & $p<0.001$ & $p<0.001$ \\
\hline \multicolumn{6}{|l|}{ Acetaminophen } \\
\hline Preoperative use ${ }^{a}$ & 1764 & $\begin{array}{l}1162 \\
(65.9 \%)\end{array}$ & $\begin{array}{l}669 \\
(37.9 \%)\end{array}$ & $\begin{array}{l}569 \\
(32.3 \%)\end{array}$ & $\begin{array}{l}507 \\
(28.7 \%)\end{array}$ \\
\hline \multirow[t]{2}{*}{ No preoperative use ${ }^{b}$} & 11,975 & $\begin{array}{l}3796 \\
(31.7 \%)\end{array}$ & $\begin{array}{l}881 \\
(7.4 \%)\end{array}$ & $\begin{array}{l}812 \\
(6.8 \%)\end{array}$ & $\begin{array}{l}896 \\
(7.5 \%)\end{array}$ \\
\hline & & $p<0.001$ & $p<0.001$ & $p<0.001$ & $p<0.001$ \\
\hline \multicolumn{6}{|l|}{ NSAID } \\
\hline Preoperative use $\mathrm{a}^{\mathrm{a}}$ & 4078 & $\begin{array}{l}2947 \\
(72.3 \%)\end{array}$ & $\begin{array}{l}1440 \\
(35.3 \%)\end{array}$ & $\begin{array}{l}1211 \\
(29.7 \%)\end{array}$ & $\begin{array}{l}1032 \\
(25.3 \%)\end{array}$ \\
\hline \multirow[t]{2}{*}{ No preoperative use ${ }^{b}$} & 9661 & $\begin{array}{l}5181 \\
(53.6 \%)\end{array}$ & $\begin{array}{l}1102 \\
(11.4 \%)\end{array}$ & $\begin{array}{l}912 \\
(9.4 \%)\end{array}$ & $\begin{array}{l}885 \\
(9.2 \%)\end{array}$ \\
\hline & & $p<0.001$ & $p<0.001$ & $p<0.001$ & $p<0.001$ \\
\hline \multicolumn{6}{|l|}{ Mild opioid } \\
\hline Preoperative use $\mathrm{a}^{\mathrm{a}}$ & 1510 & $\begin{array}{l}903 \\
(59.8 \%)\end{array}$ & $\begin{array}{l}476 \\
(31.5 \%)\end{array}$ & $\begin{array}{l}414 \\
(27.4 \%)\end{array}$ & $\begin{array}{l}384 \\
(25.4 \%)\end{array}$ \\
\hline \multirow[t]{2}{*}{ No preoperative use $\mathrm{e}^{\mathrm{b}}$} & 12,229 & $\begin{array}{l}3159 \\
(25.8 \%)\end{array}$ & $\begin{array}{l}549 \\
(4.5 \%)\end{array}$ & $\begin{array}{l}452 \\
(3.7 \%)\end{array}$ & $\begin{array}{l}521 \\
(4.3 \%)\end{array}$ \\
\hline & & $p<0.001$ & $p<0.001$ & $p<0.001$ & $p<0.001$ \\
\hline \multicolumn{6}{|l|}{ Strong opioid } \\
\hline Preoperative use $\mathrm{a}^{\mathrm{a}}$ & 58 & $\begin{array}{l}34 \\
(58.6 \%)\end{array}$ & $\begin{array}{l}24 \\
(41.4 \%)\end{array}$ & $\begin{array}{l}24 \\
(41.4 \%)\end{array}$ & $\begin{array}{l}16 \\
(27.6 \%)\end{array}$ \\
\hline \multirow[t]{2}{*}{ No preoperative use ${ }^{b}$} & 13,681 & $\begin{array}{l}251 \\
(1.8 \%)\end{array}$ & $\begin{array}{l}30 \\
(0.2 \%)\end{array}$ & $\begin{array}{l}39 \\
(0.3 \%)\end{array}$ & $\begin{array}{l}30 \\
(0.2 \%)\end{array}$ \\
\hline & & $p<0.001$ & $p<0.001$ & $p<0.001$ & $p<0.001$ \\
\hline \multicolumn{6}{|c|}{ Medication used for neuropathic pain } \\
\hline Preoperative use $^{a}$ & 454 & $\begin{array}{l}278 \\
(61.2 \%)\end{array}$ & $\begin{array}{l}275 \\
(60.6 \%)\end{array}$ & $\begin{array}{l}283 \\
(62.3 \%)\end{array}$ & $\begin{array}{l}246 \\
(54.2 \%)\end{array}$ \\
\hline \multirow[t]{2}{*}{ No preoperative use $\mathrm{b}^{\mathrm{b}}$} & 13,285 & $\begin{array}{l}165 \\
(1.2 \%)\end{array}$ & $\begin{array}{l}168 \\
(1.3 \%)\end{array}$ & $\begin{array}{l}197 \\
(1.5 \%)\end{array}$ & $\begin{array}{l}252 \\
(1.9 \%)\end{array}$ \\
\hline & & $p<0.001$ & $p<0.001$ & $p<0.001$ & $p<0.001$ \\
\hline
\end{tabular}

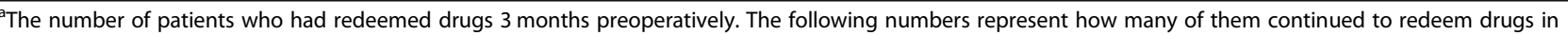
different time periods postoperatively (i.e. old users)

${ }^{\mathrm{b}}$ The number of patients who had not redeemed drugs 3 months preoperatively. The following numbers represent how many of them redeemed drugs in different time periods postoperatively (i.e. new users)

higher in women than men during the whole study period, with the only exception being the immediate postoperative period (Appendix 2, Table 2). During the study period, the proportion of patients who redeemed medications used for neuropathic pain was higher in women than in men, whereas there were no differences in the use of strong opioids, except on late postoperative period (Appendix 2, Table 2).

\section{Age}

The proportion of patients who redeemed acetaminophen was higher in older age groups (compared to the youngest age group) (Table 2). A higher proportion of younger patients redeemed NSAID's. In older patients, the proportion of patients who had redeemed at least one type of analgesic drug was higher after surgery compared to younger patients 
(Table 2). The difference according to age was mostly attributable to hip surgery: two years after surgery $20 \%$ of patients $<65$ years, $22 \%$ of patients $65-75$ years, and $28 \%$ of patients $>75$ years redeemed any analgesics $(p<0.001)$, compared to 31,29 , and $30 \%$ $(p=0.609)$, respectively.

\section{Discussion}

This large, regionally all-inclusive study of primary hip and knee replacement patients with primary osteoarthritis shows an increase in the proportion of patients using analgesic drugs before surgery, a peak in use during the immediate postoperative period, and a decrease in the late postoperative period. A surprisingly large share of patients does not use any analgesics preoperatively. However, those who use analgesics preoperatively, are more likely to use them also postoperatively, and one-fifth of hip and almost one-third of knee replacement recipients still use analgesics two years after surgery. These results expand the existing knowledge [13] by showing prescription trajectories have similar pattern in hip and knee replacements but use of analgesics is more common in knee than hip replacement patients after surgery. Use of strong opioids and drugs for neuropathic pain was rare and mostly limited to patients who were using these agents already before surgery.

The observed user rates of analgesic drugs were lower than in earlier studies [12-14, 20]. Variations in study designs may be one explaining factor. Some patients may have used only OTC drugs, leading to underestimation of user rates. Although approximately one-fourth of all NSAIDs are bought over-the-counter [22], the share is probably clearly smaller on patients with chronic painful conditions, like osteoarthritis, because in Finland only small packs of acetaminophen, ibuprofen, and ketoprofen are available OTC and they are more expensive than prescribed analgesics. Furthermore, it is unlikely that the use of OTC drugs could explain the differences of user rates between studied groups of patients. Nevertheless, in accordance with earlier studies $[13,20]$, there is indeed a surprisingly large proportion $(27 \%)$ of patients who did not redeem any prescription analgesic drugs during the year before surgery, although pain is the crucial indication for joint replacement $[1,4]$. One explanation could be that in some patients the functional impairment and deformity of the operated joint rather than pain has been the main indication for surgery. Additionally, only half of the knee osteoarthritis patients have constant pain, instead, the pain in knee osteoarthritis is typically intermittent weight-bearing pain, and quite often it is unpredictable, too [23, 24].

The proportions of patients using acetaminophen, NSAIDs, and opioids in the late postoperative period were surprisingly high both after hip and knee replacement, again in line with earlier studies [13-15, 17, 18]. The user rates of NSAIDs decreased to a lower level postoperatively than that observed two years preoperatively whereas a small increase was found in acetaminophen, mild opioids, and medications used for neuropathic pain. A possible explanation is persistent postoperative pain which is more common after knee replacement and may affect even one fifth of the patients [9]. Use of analgesics was greater in women who are known to report more osteoarthritis pain and acute procedural pain than men [22, 23]. They also have more persistent postoperative pain [19, 25-27]. Although patients with other joint replacements during the follow-up period were excluded, a multi-joint osteoarthritis and other chronic musculoskeletal conditions are a very likely reason for prolonged analgesic use particularly in the oldest age groups. Unlike some other countries, however, addiction is an unlike explanation, because there has not been an opioid epidemic in Finland and the user rates of opioids were relatively small.

The proportion of patients who redeemed acetaminophen, NSAIDs, or mild opioids increased preoperatively more in hip than in knee replacement patients. Postoperatively, the decrease was higher on hip patients, which has been shown in NSAIDs before [20]. No change in user rates was seen after 9 months in hip replacement patients, but the user rates in knee replacement patients decreased until 12 months postoperatively, which may be related to the longer recovery period after knee replacement. Furthermore, user rates for all the studied medications were higher among knee than hip replacement patients for the whole postoperative follow-up period. A higher prevalence of persistent postsurgical pain following knee replacement may at least partly explain this finding [9].

NSAIDs were the most common analgesic drugs which is in line with the results of previous studies and guidelines [1, $2,4,13,15]$, although the user rates were somewhat lower than in previous studies [12-14, 20,28,29]. Although the efficacy and safety of acetaminophen in the treatment of chronic osteoarthritis pain has been questioned recently [30-32], the drug is safe and widely used among osteoarthritis patients $[10,11,13-15]$. In this study, it was the second most commonly drug used, and like other analgesics, its use was clearly reduced after surgery. Interestingly, approximately twice as many patients redeemed acetaminophen in the late postoperative period than in the early preoperative period. It is possible that especially in the oldest age-groups patients have changed from NSAIDs to acetaminophen because of the risks related to chronic use of NSAIDs [33].

User rates of opioids were lower than expected. Earlier, between 24 and 59\% of patients have used opioids (mild and strong opioids have usually been analyzed together) 1 to 2 years before joint replacement $[11,14,16,17,29,34]$, whereas in this study 
the proportions were around 15 and $10 \%$ in hip and knee patients three months before surgery, respectively. Similar observation was made also when drug use was analyzed for one year period. The reason for this difference is unclear. Although it should be noted that these results originate from one hospital district, it seems that at population level the overall prevalence of dispensed opioids is lower in Finland (6\% in year 2016) [35] than in other Nordic countries (8$12 \%$ in women and $6-9 \%$ in men in year 2016) [36] or in the United States (17\% in year 2017) [37]. Also, the total consumption of opioid analgesics measured in DDD has been lower in Finland [38]. Another explanation might be that opioid prescription has been controlled more tightly in Finland than in some other countries, and a special prescription form which is not possible to copy was needed for strong opioids at the time of this study. All in all, the prevalence of any opioid use was higher in our cohort compared to Finnish population, which is in line with earlier findings (in Sweden 9.6\% on individuals without OA compared to $23.7 \%$ on individuals with OA) [39].

It is noteworthy, that the number of long-term users of opioids did not increase remarkably after joint replacement, and only a minority of patients were new users of opioids 2 years after hip and knee replacement ( 3 and 5\%, respectively). The consumption of opioids was mostly related to the perioperative phase. Use of strong opioids was rare (less than $0.5 \%$ ), and only a minority were new users of strong opioids after surgery $(0.2 \%)$.

Unlike the other analgesics, the user rates of medication used for neuropathic pain did not have a clear association with the time of surgery, suggesting that the indication for the use of these drugs is probably other than osteoarthritis. However, it has been estimated that a neuropathic component is present in one-third of patients with painful osteoarthritis [40, 41] and some patients could benefit from medication used for neuropathic pain. In line with earlier studies $[11,15]$, the user rates increased during the study period, especially in knee replacement patients. Prolonged postoperative pain is a possible explanation for this observation $[9,42]$.

There are several strengths in this register study, including the large sample size of an unselected population sample undergoing hip or knee replacement for osteoarthritis. Medication data were extracted from a publicly funded nationwide prescription register with practically complete coverage. Only a few studies have analyzed data of all analgesic drug classes from national registers $[11,13,15]$. We believe that the inclusion of all analgesic drug groups is essential to understand the trends of analgesic consumption before and after joint replacement. However, all these previous studies show the user rates only one year pre- and postoperatively. In this study, the user rates were analyzed two years before the surgery to find out at which point the proportion of users starts to increase, and two years postoperatively to find out whether analgesic use stabilize one year after surgery. Patients with revision or other joint replacement during the follow-up period were excluded, so hip and knee pain on other joints should not hamper the results. All operations were performed in a single orthopedic hospital with a standardized perioperative anesthesia and analgesia.

Register-based studies also have limitations. The pharmacological dispensing data do not inform whether the drug was redeemed because of pain in the operated joint or whether the patient has taken the drug or not. A daily diary of analgesic drug use could give more accurate information on the topic. We did not analyze amounts of drugs used, and inclusion of DDDs (defined daily dose) or OMEQs (oral morphine equivalents) could give more information on this topic. However, the perceptions of pain and the amounts of analgesics used are individual, and the value of reporting proportions of users is that it tells whether there is need or no need for analgesics. We were not able to analyze OTC drugs and topical NSAIDs that may have been used in addition to or instead of prescription analgesics and hence the actual use of analgesics may have been even greater than we observed. In the case of irregular use, purchases of analgesics can occur with longer intervals, and therefore the proportion of users may be underestimated in studies based on register data. A multijoint osteoarthritis is one confounding factor and we were not able to analyze pain on non-target joints. The intensity of pain and the prevalence of persistent pain could not be evaluated in this study. Although the population was unselected and included all the patients of the region, the generalizability of the results may be limited, because all surgeries were performed in the same hospital, and both indications for joint replacement and prescription practices may vary in different regions even though there are national guidelines for both. It should be noted that due to the large sample size, even minor differences may appear statistically significant.

\section{Conclusions}

In conclusion, the use of analgesic drugs increases before joint replacement surgery, and both hip and knee replacement lead to reduction in the use of pain medications, although the change is lesser after knee replacement. The reductions in the user rates were similar for acetaminophen, NSAIDs and opioids whereas use of medications for neuropathic pain seems to increase slightly. A substantial number of patients continue to use analgesics up to two years after surgery. 


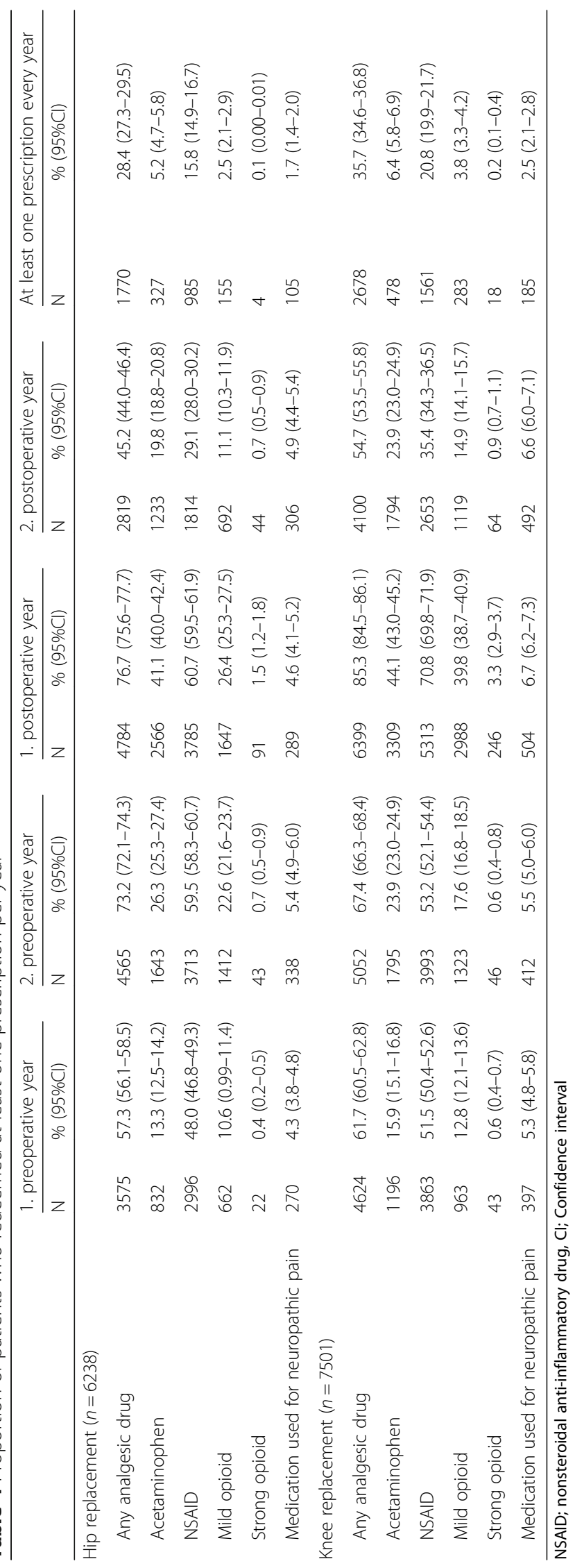




\section{Appendix 2}

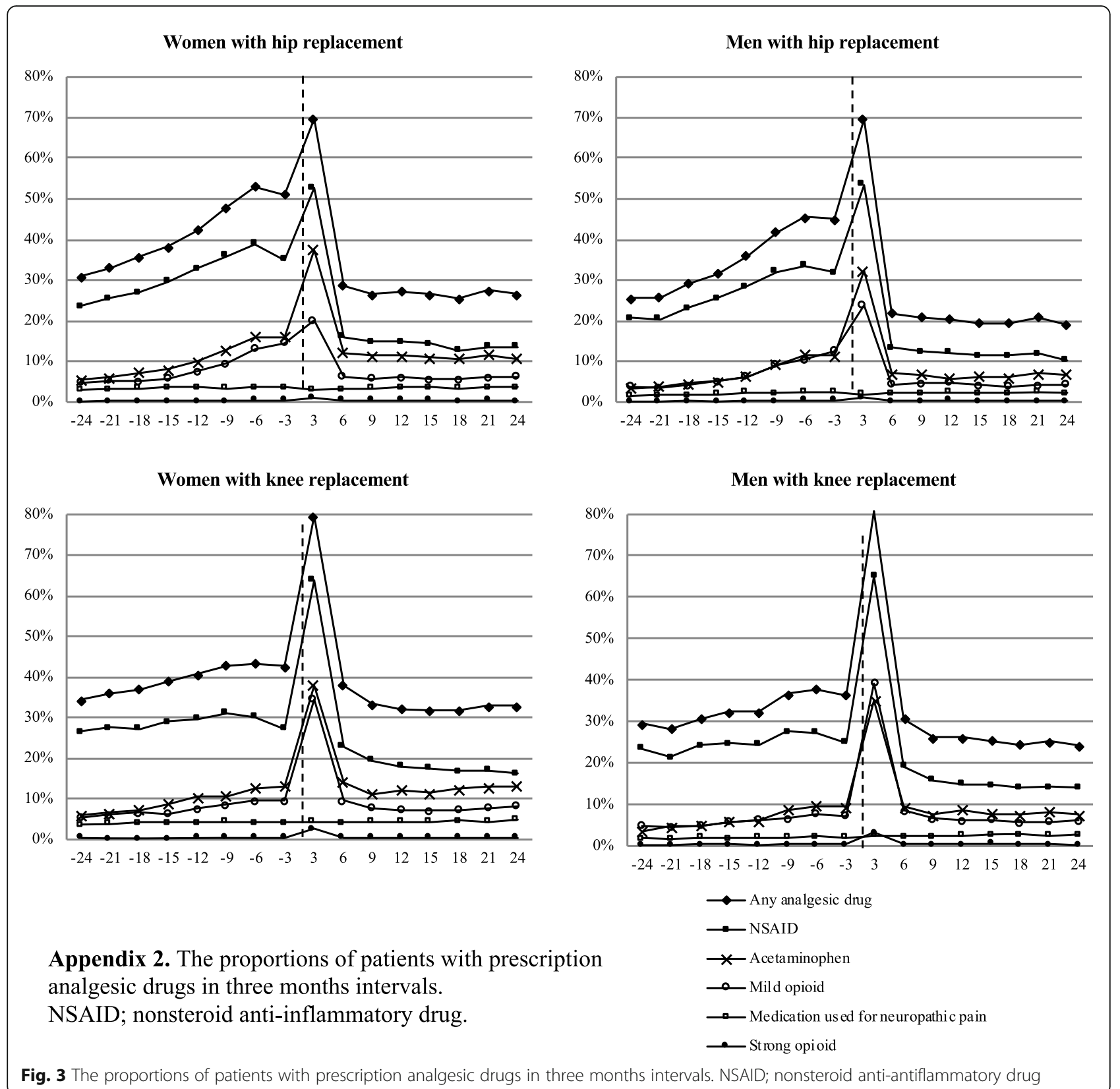

\section{Abbreviations}

ATC code: Anatomical Therapeutic Chemical code; Cl: Confidence interval; DDD: Defined daily dose; NSAID: Anti-inflammatory drug; OA: Osteoarthritis; OMEQ: Oral morphine equivalent; OTC drug: Over-the-counter drug;

SD: Standard deviation

\section{Acknowledgements}

We thank Heini Huhtala, M.Sc., for her assistance with statistical analyses.

\section{Authors' contributions}

EJ, TR, TM, PP, and AH designed the study. TR analyzed the data, wrote the first draft of the manuscript and took care of its revisions under supervision of EJ. All the authors contributed to interpretation of the results and preparation of the manuscript. All authors approved the final version of the manuscript.

\section{Authors' information}

Not applicable.

\section{Funding}

This study was financially supported by the Competitive State Research Financing of the Expert Responsibility area of Tampere University Hospital. The Funding organization did not have any role in design of the study or collection, analysis, and interpretation of data or in writing the manuscript. 


\section{Availability of data and materials}

National legislation and data protection regulations do not allow sharing patient-level materials of this study. Summarized data (like patient numbers) can be provided by corresponding author upon request.

\section{Ethics approval and consent to participate}

The study was approved by The Social Insurance Institution of Finland (Kela), from where the medication data was extracted and by the hospital, from where the clinical data was extracted. Because this is a retrospective register study, consent from the patients or from the Ethical Board is not needed, according to Finnish and EU legislation.

\section{Consent for publication}

Not applicable.

\section{Competing interests}

EJ, TM and AH have received payments for lectures not related to this manuscript from pharmaceutical or other medical companies.

\section{Author details \\ ${ }^{1}$ Faculty of Medicine and Health Technology, Tampere University, Fl-33014 Tampere, Finland. ${ }^{2}$ Department of Emergency Medicine and Anaesthesia, Tampere University Hospital, PO box 2000, Fl-33521 Tampere, Finland. ${ }^{3}$ Department of Neurology, Tampere University Hospital, PO box 2000, Fl-33521 Tampere, Finland. ${ }^{4}$ Coxa, Hospital for Joint Replacement, PO box 652, FI-33101 Tampere, Finland.}

\section{Received: 17 May 2019 Accepted: 30 August 2019}

\section{Published online: 14 September 2019}

\section{References}

1. Zhang W, Nuki G, Moskowitz RW, Abramson S, Altman RD, Arden NK, et al. OARSI recommendations for the management of hip and knee osteoarthritis. Part III: changes in evidence following systematic cumulative update of research published through January 2009. Osteoarthr Cartil [Internet]. 2010;18(4):476-99 Available from: https://doi.org/10.1016/j.joca. 2010.01.013.

2. Hochberg MC, Altman RD, April KT, Benkhalti M, Guyatt G, McGowan J, et al. American College of Rheumatology 2012 recommendations for the use of nonpharmacologic and pharmacologic therapies in osteoarthritis of the hand, hip, and knee. Arthritis Care Res (Hoboken) [Internet]. 2012;64(4):465-74 Available from: http://www.ncbi.nlm.nih. gov/pubmed/22563589.

3. Larmer PJ, Reay ND, Aubert ER, Kersten P. Systematic review of guidelines for the physical Management of Osteoarthritis. Arch Phys Med Rehabil [Internet]. 2014;95(2):375-89 Available from: http://linkinghub.elsevier.com/ retrieve/pii/S0003999313011052.

4. National Institute for Health and Clinical Excellence. NICE guideline on osteoarthritis: The care and management of osteoarthritis in adults, NICE clinical guideline 177, 2014. Online document at: http://guidance.nice.org. uk/CG177 Accessed February 19, 20. Available from: https://www.nice.org. uk/guidance/cg59

5. Working group set up by the Finnish Medical Society Duodecim and the Finnish Orthopaedic Association. Knee and hip osteoarthritis (online). Current care guidelines. Helsinki: The Finnish Medical Society Duodecim, 2012 (referred April 13, 2018). Available.

6. Carr AJ, Robertsson O, Graves S, Price AJ, Arden NK, Judge A, et al. Knee replacement. Lancet (London, England) [Internet] 2012 [cited 2017 Jan 23]; 379(9823):1331-1340. Available from: http://linkinghub.elsevier.com/retrieve/ pii/S0140673611607526

7. Shan L, Shan B, Graham D, Saxena A. Total hip replacement: a systematic review and meta-analysis on mid-term quality of life. Osteoarthr Cartil [Internet]. 2014;22(3):389-406 Available from: http://linkinghub.elsevier.com/ retrieve/pii/S106345841301039X.

8. Shan L, Shan B, Suzuki A, Nouh F, Saxena A. Intermediate and long-term quality of life after Total knee replacement. J Bone Jt Surg [Internet]. 2015; 97(2):156-68 Available from: http://insights.ovid.com/crossref?an= 00004623-201501210-00010.

9. Beswick AD, Wylde V, Gooberman-Hill R, Blom A, Dieppe P. What proportion of patients report long-term pain after total hip or knee replacement for osteoarthritis? A systematic review of prospective studies in unselected patients. BMJ Open [Internet]. 2012;2(1):e000435 Available from: http:// bmjopen.bmj.com/lookup/doi/10.1136/bmjopen-2011-000435.

10. Kingsbury SR, Hensor EMA, Walsh CAE, Hochberg MC, Conaghan PG. How do people with knee osteoarthritis use osteoarthritis pain medications and does this change over time? Data from the osteoarthritis initiative. Arthritis Res Ther [Internet]. 2013;15(5):R106 Available from: http://arthritis-research. biomedcentral.com/articles/10.1186/ar4286.

11. Fuzier R, Serres I, Bourrel R, Palmaro A, Montastruc J-L, Lapeyre-Mestre M. Analgesic drug consumption increases after knee arthroplasty: A pharmacoepidemiological study investigating postoperative pain. Pain [Internet]. 2014 [cited 2018 Apr 14];155(7):1339-1345. Available from: http:// content.wkhealth.com/linkback/openurl?sid=WKPTLP:landingpage\&an= 00006396-201407000-00024

12. Dusad A, Pedro S, Mikuls TR, Hartman CW, Garvin KL, O'Dell JR, et al. Impact of Total knee arthroplasty as assessed using patient-reported pain and health-related quality of life indices: rheumatoid arthritis versus osteoarthritis. Arthritis Rheumatol [Internet]. 2015;67(9):2503-11 Available from: http://www.ncbi.nlm.nih.gov/pubmed/26213106.

13. Blågestad T, Nordhus IH, Grønli J, Engesæter LB, Ruths S, Ranhoff AH, et al. Prescription trajectories and effect of total hip arthroplasty on the use of analgesics, hypnotics, antidepressants, and anxiolytics. Pain [Internet]. 2016 [cited 2018 Apr 14];157(3):643-651. Available from: https://insights.ovid.com/ crossref?an $=00006396-201603000-00016$

14. Inacio MCS, Cashman K, Pratt NL, Gillam MH, Caughey G, Graves SE, et al. Prevalence and changes in analgesic medication utilisation 1 year prior to total joint replacement in an older cohort of patients. Osteoarthr Cartil [Internet]. 2018;26(3):356-62 Available from: https://doi. org/10.1016/j.joca.2017.11.016.

15. Jørgensen CC, Petersen M, Kehlet $H$, Aasvang EK. Analgesic consumption trajectories in 8975 patients 1 year after fast-track total hip or knee arthroplasty. Eur J Pain. 2018;22(April):1428-38.

16. Goesling J, Moser SE, Zaidi B, Hassett AL, Hilliard P, Hallstrom B, et al. Trends and predictors of opioid use after total knee and total hip arthroplasty. Pain [Internet]. 2016 Jun [cited 2018 Apr 14];157(6):1259-1265. Available from: https://insights.ovid.com/crossref?an=00006396-201606000-00012

17. Hansen CA, Inacio MCS, Pratt NL, Roughead EE, Graves SE. Chronic use of opioids before and after Total knee arthroplasty: a retrospective cohort study. J Arthroplast [Internet]. 2017;32(3):811-817.e1 Available from: https:// doi.org/10.1016/j.arth.2016.09.040

18. Inacio MCS, Hansen C, Pratt NL, Graves SE, Roughead EE. Risk factors for persistent and new chronic opioid use in patients undergoing total hip arthroplasty: a retrospective cohort study. BMJ Open [Internet]. 2016;6(4):e010664 Available from: http://bmjopen.bmj.com/lookup/doi/10.1136/bmjopen-2015-010664.

19. Singh $J A$, Lewallen $D$. Predictors of pain and use of pain medications following primary Total hip arthroplasty (THA): 5,707 THAs at 2-years and 3,289 THAs at 5-years. BMC Musculoskelet Disord [Internet]. 2010[cited 2018 Apr 14];11(1):90. Available from: http://bmcmusculoskeletdisord. biomedcentral.com/articles/10.1186/1471-2474-11-90

20. Bolland BJRF, Culliford DJ, Maskell J, Latham JM, Dunlop DG, Arden NK. The effect of hip and knee arthroplasty on oral anti-inflammatory use and the relationship to body mass index: results from the UK general practice research database. Osteoarthr Cartil [Internet]. 2011;19(1):29-36 Available from: https://doi.org/10.1016/j.joca.2010.10.012.

21. Singh $J A$, Lewallen DG. Predictors of use of pain medications for persistent knee pain after primary Total Knee Arthroplasty: a cohort study using an institutional joint registry. Arthritis Res Ther [Internet]. 2012[cited 2018 Apr 14];14(6):R248. Available from: http://arthritis-research.biomedcentral.com/ articles/10.1186/ar4091

22. Finnish Statistics on Medicines 2007. National Agency for Medicines (NAM) and the Social Insurance Institution (Kela). Helsinki; 2008. Available from: https://www.kela.fi/documents/12099/12170/laaketilasto07_2.pdf.

23. Hunter DJ, Bierma-Zeinstra S. Osteoarthritis. Lancet. 2019;393(10182):174559. https://doi.org/10.1016/S0140-6736(19)30417-9.

24. Liu A, Kendzerska T, Stanaitis I, Hawker G. The relationship between knee pain characteristics and symptom state acceptability in people with knee osteoarthritis. Osteoarthr Cartil [Internet]. 2014;22(2):178-83 Available from: https://doi.org/10.1016/j.joca.2013.11.012.

25. Fillingim RB, King CD, Ribeiro-Dasilva MC, Riley $J \mathrm{~L} I I I$. Sex, gender, and pain: a review of recent clinical and experimental findings. J Pain [Internet]. 2009; 10(5):447-85 Available from: http://www.sciencedirect.com/science/article/ pii/S1526590008009097. 
26. Lavand'homme P, Thienpont E. Pain after total knee arthroplasty: a narrative review focusing on the stratification of patients at risk for persistent pain. Bone Joint J [Internet]. 2015[cited 2017 Jan 23];97-B(10 Suppl A):45-48. Available from: http://www.bjj.boneandjoint.org.uk/cgi/doi/10.1302/0301-62 OX.97B10.36524

27. Lewis GN, Rice DA, McNair PJ, Kluger M. Predictors of persistent pain after total knee arthroplasty: a systematic review and meta-analysis. Br J Anaesth. 2015;114(4):551-61.

28. Dall GF, Ohly NE, Ballantyne JA, Brenkel IJ. The influence of pre-operative factors on the length of in-patient stay following primary total hip replacement for osteoarthritis. J Bone Joint Surg Br [Internet]. 2009;91-B(4): 434-40 Available from: http://online.boneandjoint.org.uk/doi/10.1302/03 01-620X.91B4.21505.

29. Berger A, Bozic K, Stacey B, Edelsberg J, Sadosky A, Oster G. Patterns of pharmacotherapy and health care utilization and costs prior to total hip or total knee replacement in patients with osteoarthritis. Arthritis Rheum. 2011;63(8):2268-75.

30. Machado GC, Maher CG, Ferreira PH, Pinheiro MB, Lin C-WC, Day RO, et al. Efficacy and safety of paracetamol for spinal pain and osteoarthritis: systematic review and meta-analysis of randomised placebo controlled trials. BMJ [Internet]. 2015;350(mar31 2):h1225 Available from: http://www. bmj.com/cgi/doi/10.1136/bmj.h1225.

31. Ennis ZN, Dideriksen D, Vaegter HB, Handberg G, Pottegård A. Acetaminophen for chronic pain: a systematic review on efficacy. Basic Clin Pharmacol Toxicol [Internet]. 2016;118(3):184-9 Available from: http://doi. wiley.com/10.1111/bcpt.12527.

32. da Costa BR, Reichenbach S, Keller N, Nartey L, Wandel S, Jüni P, et al. Effectiveness of non-steroidal anti-inflammatory drugs for the treatment of pain in knee and hip osteoarthritis: a network meta-analysis. Lancet [Internet]. 2017;390(10090):e21-33 Available from: http://linkinghub.elsevier. com/retrieve/pii/S0140673617317440.

33. Wongrakpanich S, Wongrakpanich A, Melhado K, Rangaswami J. A Comprehesive review of non-steroidal anti-inflammatory drug use in the elderly. Aging Dis. 2018;9(1):143-50.

34. Franklin PD, Karbassi JA, Li W, Yang W, Ayers DC. Reduction in narcotic use after primary total knee arthroplasty and association with patient pain relief and satisfaction. J Arthroplasty [Internet]. 2010;25(6 Suppl):12-6 Available from: http://linkinghub.elsevier.com/retrieve/pii/S0883540310002950.

35. Official Statistics of Finland: available at http://raportit.kela.fi/ibi_apps/ WFServlet. Accessed on Aug 22019.

36. Muller AE, Clausen T, Sjogren P, Odsbu I, Skurtveit S. Prescribed opioid analgesic use developments in three Nordic countries, 2006-2017. Scand J Pain. 2019;19(2):345-53.

37. Centers for Disease Control and Prevention. 2018 Annual surveillance report of drug-related risks and outcomes - United States. Surveillance special report 2. Centers for Disease Control and Prevention, U.S. Department of Health and Human Services. Publis.

38. Hamunen $\mathrm{K}$, Paakkari P, Kalso E. Trends in opioid consumption in the Nordic countries 2002-2006. Eur J Pain [Internet]. 2009;13(9):954-62 Available from: https://doi.org/10.1016/j.ejpain.2008.11.006.

39. Thorlund JB, Turkiewicz A, Prieto-alhambra D, Englund M. Opioid use in knee or hip osteoarthritis : a region-wide population- based cohort study. 2019;27(6):871-7. https://doi.org/10.1016/j.joca.2019.01.005.

40. Dimitroulas T, Duarte RV, Behura A, Kitas GD, Raphael JH. Neuropathic pain in osteoarthritis: a review of pathophysiological mechanisms and implications for treatment. Semin Arthritis Rheum [Internet]. 2014;44(2): 145-54 Available from: http://linkinghub.elsevier.com/retrieve/pii/S004 901721400105X

41. Perrot S. Targeting pain or osteoarthritis? Implications. PAIN Clin Updat [Internet]. 2016;24(2):1-8 Available from: https://www.iasp-pain.org/files/ Content/ContentFolders/Publications2/PainClinicalUpdates/PCU24-2.Perrot. WebFINALpdf.pdf.

42. Petersen KK, Arendt-Nielsen L. Chronic postoperative pain after joint replacement. Pain. 2016;24(3):1-6.

\section{Publisher's Note}

Springer Nature remains neutral with regard to jurisdictional claims in published maps and institutional affiliations.

\section{Ready to submit your research? Choose BMC and benefit from}

- fast, convenient online submission

- thorough peer review by experienced researchers in your field

- rapid publication on acceptance

- support for research data, including large and complex data types

- gold Open Access which fosters wider collaboration and increased citations

- maximum visibility for your research: over $100 \mathrm{M}$ website views per year

At $\mathrm{BMC}$, research is always in progress.

Learn more biomedcentral.com/submissions 